\title{
XLVI. Notice of a geological survey of the mines of Cornwall; with a programme of an intended arrangement of the leading details of the metalliferous veins, \&c
}

\section{W. Jory Henwood F.G.S.}

To cite this article: W. Jory Henwood F.G.S. (1831) XLVI. Notice of a geological survey of the mines of Cornwall; with a programme of an intended arrangement of the leading details of the metalliferous veins, \&c, Philosophical Magazine Series 2, 10:59, 358-363, DOI: $10.1080 / 14786443108675558$

To link to this article: http://dx.doi.org/10.1080/14786443108675558

$$
\text { 冓 Published online: } 14 \text { Jul } 2009 .
$$

Submit your article to this journal $\sqsubset$

$$
\text { Џll Article views: } 2
$$

Q View related articles ¿ 
the work of an all-wise, all-powerful Deity, can only be hoped for from a cautious process of inductive and analogical reasoning." And yet this stuff is put within commas, as if I had written it. Allow me to say also, in reply to the editorial note affixed to this singular quotation, that I have nowhere designated " any attempt to unravel" the Plan of the Creation, as the Natural System.

By the way of conclusion, I may remark that your Correspondent is happily not in any way obliged to trouble his brains with the "repulsive and inscrutable" innovations of "revolutionary Zoologists." And therefore advising and hoping that in future he will stick close to "the familiar and popular Entomology" which amused him "in those happy days long gone by," I remain, my dear Sir, yours \&c.

W. S. MacLeay.

XLVI. Notice of a Geological Survey of the Mines of Cornroall; with a Programme of an intended Arrangement of the leading Details of the Metalliferous Veins, \&c. By W. Jory Henwood, F.G.S.

Dear Sir,

To Richard Taylor, Esq. \&c. \&c.

IN the year 1829, at the desire of R. W. Fox, Esq. of Falmouth, and C. Fox, Esq. of this place, who also defrayed the expenses incidental thereon, I made an examination of the leading geological features of several of the mines in Cornwall; and a short residence in the neighbourhood of Tavistock, in the summer of 1830, afforded me an opportunity of extending my investigations to some of the mines there. The results of these inquiries were communicated to the Royal Geological Society of Cornwall, in October last, and were to have been honoured with a place in the forth-coming fourth volume of their Transactions.

But in consequence of the liberal aid and encouragement of most of the noblemen and gentlemen resident in, and connected with, this county, as well as of several distinguished scientific men elsewhere, I have commenced a survey of all the mines in Cornwall; and I have now examined all those west of Redruth. Besides noticing the geological relations of the veins, ("lodes", "cross courses," "flucans," "slides," and " elvan courses",) and of the rocks they traverse, I ascertain the temperature of every stream I find running or jetting out of the unbroken rock, and make experiments on the electromagnetic properties of the veins*.

After having gone through all the mines, I shall endeavour to arrange and classify my observations; and the Council of

$$
\text { * Fox, Phil. Trans. 1830, frart ii. }
$$


the Cornwall Geological Society have kindiy permitted me to withdraw the before-mentioned paper, in order to its being incorporated with the rest. When completed, I intend leaving my work at the disposal of the noblemen and gentlemen whose liberal assistance has mainly contributed to its completion. But before I proceed, I am anxious to submit to your geological readers a Programme of the manner in which I had intended arranging the details, and I shall be exceedingly obliged to any of them who will trouble themselves to point out the defects, and to suggest improvements. Those who are unacquainted with the interior of a mine will doubtless notice in this outline many points of interest not described; the contact of veins at various depths, unseen; and a general scantiness of information. I may observe, that the excavations are not always extended to the points at which interesting phænomena may be expected; operations may have been suspended, and the sides of the excavations either fallen together, been filled with water, or with foul air which extinguishes candles; the vein may have been entirely worked away, and in most cases the sides are after a short period invested with a crust of ferruginous matter, which rapidly accumulates. In a few instances $I$ have not deemed it prudent to expose myself to falling rubbish, on decayed wood, or on rotten ladders. None but those who have experienced the like can fully feel the many vexatious disappointments I have had to suffer, in meeting an immovable barrier sometimes but a few fathoms, or even a few feet, from my object; after having crept hundreds of fathoms on all-four, and often on the belly, through mud and water, often beneath tottering rocks. These inconveniences, to which geologists who confine themselves to the neighbourhood of the surface are not exposed, have been every-day occurrences with me; and I venture to hope that they may with some propriety be offered as an apology for the deficiencies which my outline will at every step present.

$$
\text { I remain, \&c. }
$$

Perran Wharf, near'Truro, Aingust 11, 1831.

Wm. J. Henwood.

\section{PROGRAMME.}

Cookskitchen Mine, parish of Illogan, near Redruth, is situated on the northern side of the granitic range, of which the nearest hill (Carnarthen Cairn) is only about half a mile distant, and its acclivity is at an angle of about $7^{\circ}$. The phænomena of the interlying of granite and slate which here occur have been often referred to, having for a considerable time been supposed to be peculiar to this mine. The eastern part of its surface is nearly horizontal; but towards the west it rapidly declines. 


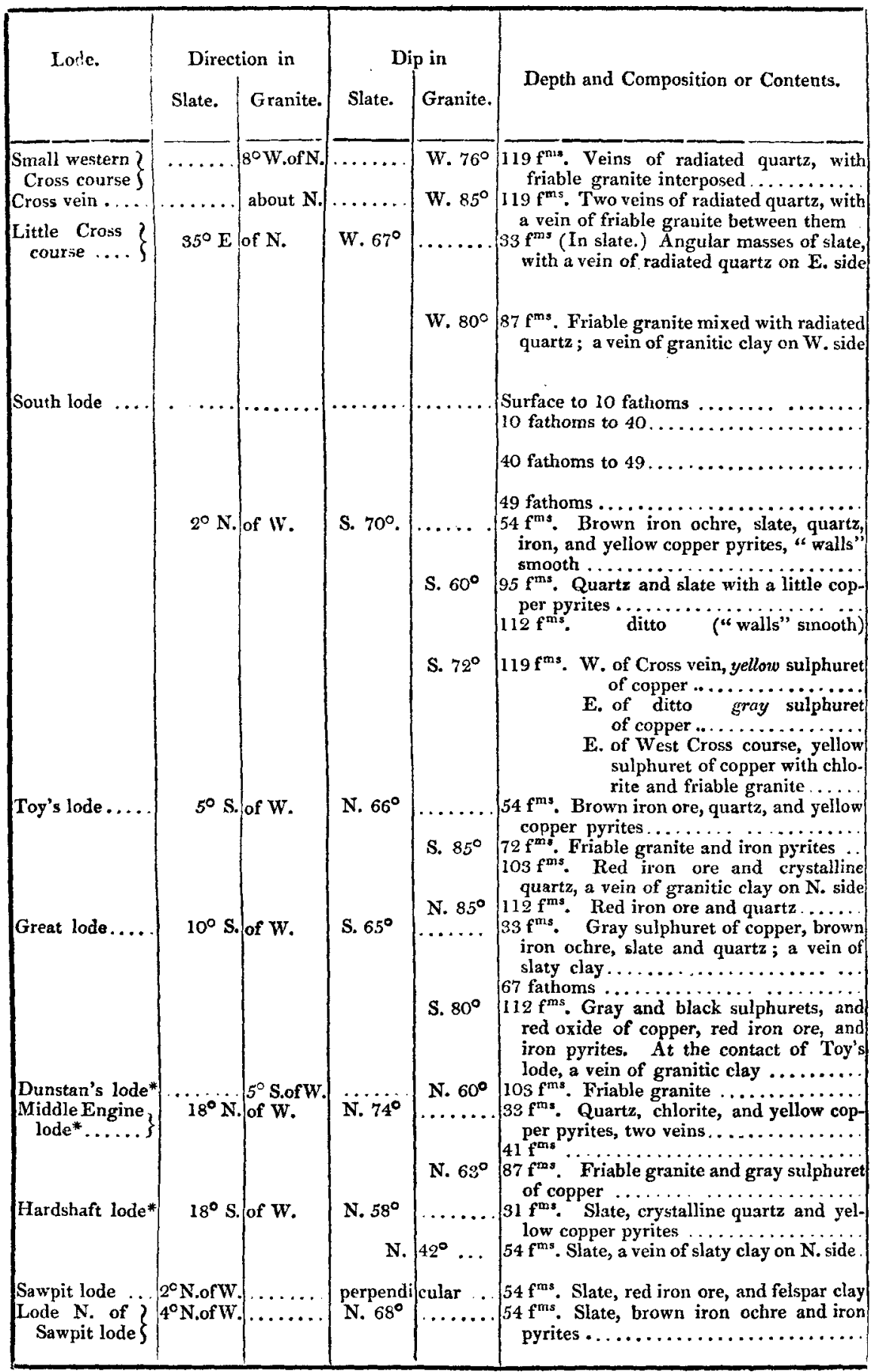

* The out-erop of these "lodes" (if there be any) is not scen. 


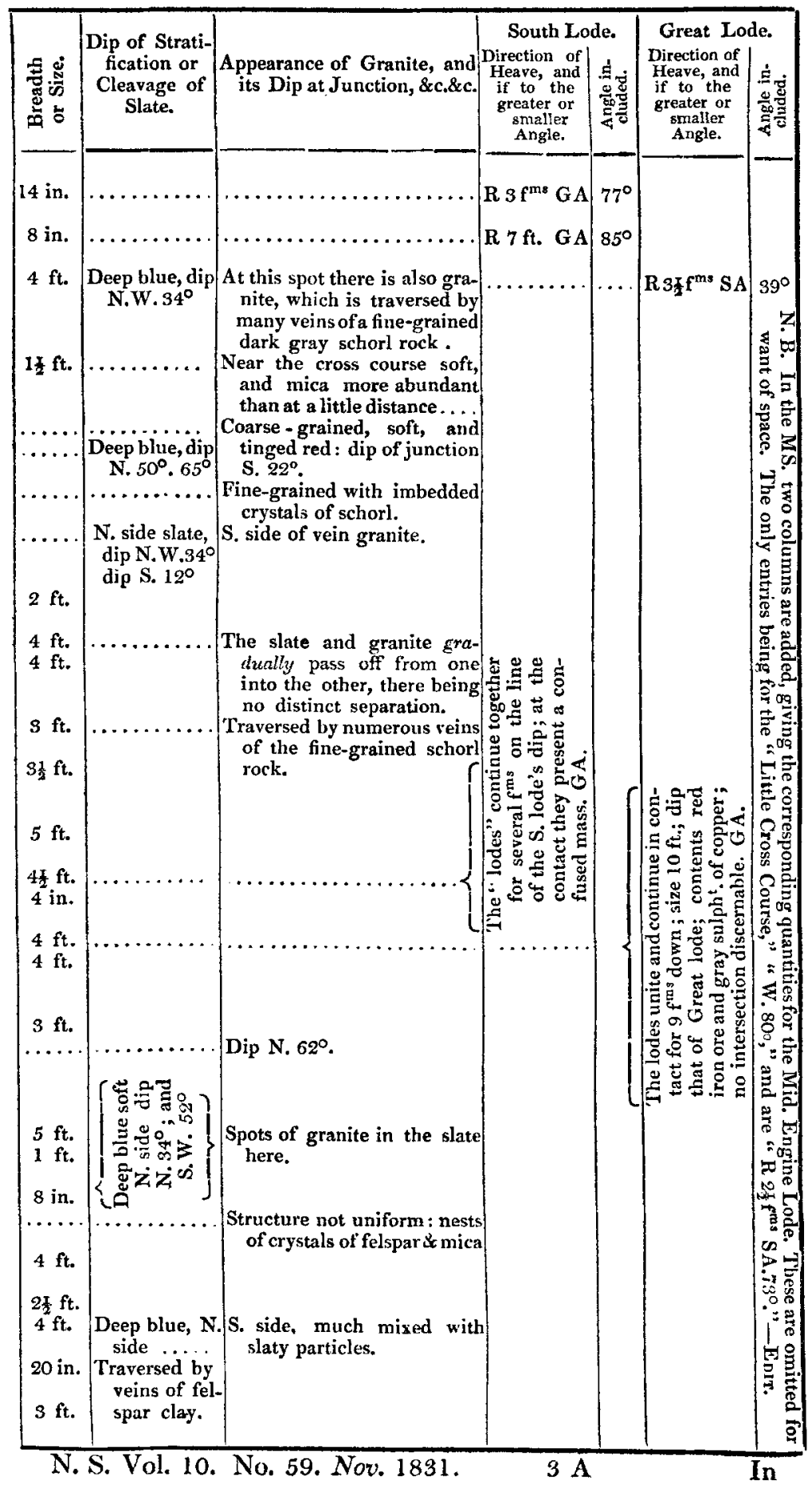




\section{Mr. Henwood's Survey of the Mines of Cornwall.}

In the preceding columns the "direction" is with regard to true north, and the dip in deviation from the horizon. When in its horizontal course one vein or lode is intersected by another, and the parts on opposite sides of the traversing vein are not exactly opposite to one another, the intersected "lode" is said to be "heaved." Whether we approach the traversing vein from the east or west, on the course of that which it has "heaved," still in either case the dislocated portion on the opposite side will be found by turning to the same hand; and thus a heave to the "right" or to the "left" is the same on either side:- this is the meaning of the letter $R$ in the foregoing Table. The GA and SA refer to whether the dislocated portion is to be found on the side of the "greater" or "smaller angle." The prevailing dip of the "bunches" of ore in Cookskitchen is to the westward; but I forbear entering on that branch of the subject, or on a discussion of the laws which may perhaps be ultimately found to regulate the distribution of metalliferous minerals, as such inquiries would be foreign to the object of this communication.

Cookskitchen Mine, Parish of Illogan, Cornwall : transverse Section.

[Seale 32 fathoms to an inch.]

Allusions to the accompanying figure. The shaded portions denote granite; the unshaded, slate. $a$ South lode; $b$ Toy's

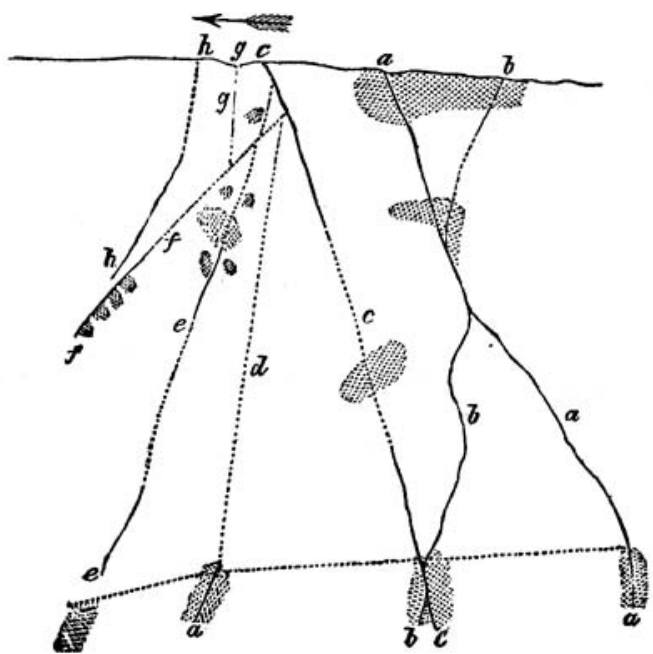

Henwood del.

lode; $c$ Great lode; $d$ Dunstan's lode; $e$ Middle Engine lode; $f$ Hardshaft 
On the Disinfecting Powers of increased Temperatures. 363

$f$ Hardshaft lode; $g$ Sawpit lode; $h$ Lode north of Sawpit lode. It seems probable that Hardshaft, Middle Engine, and Dunstan's lodes are only "branches" of the Great lode. The dotted lines respectively denote the suspected continuation of the various "lodes" and of the masses of granite;-these points are said to have been seen by others. 'The full lines denote what I have seen, the dotted portions what I have not seen.

XLVII. Experiments on the Disinfecting Porvers of increased. Temperatures, with a view to the Suggestion of a Substitute for Quarantine. By William Henry, M.D. F.R.S. \& c.

To the Editors of the Philosophical Magazine and Annais.

Gentlemen,

Manchester, Oct. 14, 1831.

GEVERAL years have elapsed since I was requested, by $N$ an eminent merchant of this town* extensively concerned in the importation of Egyptian cotton, to take into consideration, whether any effectual method could be devised of guarding against the introduction of the Plague into this country by means of that raw material, without incurring the serious commercial sacrifices, which then attended the enforcement of the quarantine laws on large cargoes of that article. Chlorine might have been proposed for the purpose; but it was evidently inapplicable, not only on account of its chemical activity on vegetable substances, but of the necessity of washing and drying the cotton, in order to free it from any adhering portions of that powerful agent, the smallest remains of which would be injurious to the spinning machinery. In proposing any new method of destroying contagious matter, it was represented to me as quite essential that it should be incapable of impairing, by its chemical action, the tenacity of the fibre, as this would unfit the raw material for the operations through which it has subsequently to pass.

By this restriction, the ground for experiment was considerably narrowed; and after giving much attention to the subject, no means occurred to me of effecting the object in view, but that of applying to the raw cotton such a degree of heat as, while it should do no injury to the staple of the article, might yet be sufficient for the destruction of any contagious virus which it might have imbibed.

That the contagion of the plague, supposing it to be present in the state of fomitest, might be rendered innoxious by a

* Williarn Garnett, Esq.

temperature

+ Fomites (the plural of jomes, fuel) expresses contagions or infections 3 A 2 matter 